\title{
Tábuas de mortalidade dos aposentados por invalidez pelo Regime Geral da Previdência Social - 1999-2002
}

\author{
Aloísio Joaquim Freitas Ribeiro* \\ Moema Gonçalves Bueno Figoli** \\ Diana Oya Sawyer ${ }^{\star * *}$ \\ Cibele Comini César ${ }^{\star \star \star *}$
}

\begin{abstract}
Neste estudo são construídas tábuas de mortalidade para os aposentados por invalidez do Regime Geral da Previdência Social brasileira, de clientela urbana, por sexo, utilizando-se os microdados relativos aos benefícios que estiveram ativos em algum instante do período entre 01/01/1999 e 31/12/2002.
\end{abstract}

Palavras-chave: Tábuas de mortalidade. Aposentados por invalidez. Regime Geral da Previdência Social. Modelo de Poisson.

\section{Introdução}

A Previdência Social brasileira define invalidez como a incapacidade do segurado para o trabalho, resultante de doença ou lesão, e insuscetível de reabilitação para o exercício de atividade que lhe garanta a subsistência (BRASIL, 1999). Com a invalidez, o trabalhador tem redução da sua renda, devido à impossibilidade de trabalhar, ao mesmo tempo em que aumentam suas despesas com os gastos decorrentes do processo de doença. Além disso, a invalidez tem conseqüências danosas sobre o bemestar do indivíduo e de sua família, as quais dependem do tipo de doença ou lesão que resultou na invalidez, da sua gravidade e das restrições para realização das atividades da vida diária.

O trabalhador pode se proteger da perda de renda decorrente da invalidez por meio da realização de um plano de previdência ou de seguro com cobertura para este evento. No Brasil, todos os segurados da Previdência Social estão cobertos contra o risco de perda de renda devido à invalidez, através do benefício de aposentadoria por invalidez.

O tratamento atuarial de um plano de previdência requer que se conheça como os segurados transitam entre os estados de atividade, aposentadoria e morte. No caso de um plano de previdência com cobertura contra o risco da perda de renda devido à invalidez, para o cálculo de prêmios, de reservas matemáticas e de outros parâmetros atuariais de interesse, bem como para realização de projeções de beneficiários e custos futuros com invalidez, é necessário que se conheçam as probabilidades de transição de um segurado entre os estados de atividade, invalidez

\footnotetext{
* Professor do Departamento de Estatística, da Universidade Federal de Minas Gerais - UFMG.

** Professora do Centro de Desenvolvimento e Planejamento Regional - Cedeplar, da Universidade Federal de Minas Gerais UFMG.

${ }_{* \star *}$ Professora do Centro de Desenvolvimento e Planejamento Regional - Cedeplar, da Universidade Federal de Minas Gerais UFMG. .

${ }_{* \star \star \star}^{*}$ Professora do Departamento de Estatística, da Universidade Federal de Minas Gerais - UFMG.
} 
e morte, as quais são, geralmente, apresentadas na forma de tábuas de vida. No caso de benefícios de aposentadorias por invalidez, além da tábua de mortalidade dos ativos, outras duas são de interesse: a tábua de entrada em invalidez, que descreve como ocorrem as transições da atividade para a invalidez; e a de mortalidade dos inválidos, que descreve como ocorrem as transições da invalidez para a morte. As tábuas de entrada em invalidez e as tábuas de mortalidade de inválidos, atualmente utilizadas no Brasil para realização de cálculos atuariais e de projeções ou simulações sobre os regimes de previdência, refletem experiências de outras populações ou experiências antigas de alguns setores de atividade da população brasileira. Evidências disso são as tábuas, definidas como parâmetros para avaliação atuarial, pela legislação referente aos planos de previdência complementar aberta (CNSP, 2002) e pela legislação referente ao Regime Próprio da Previdência Social dos Servidores Públicos (MPAS, 1999), que estabelecem a tábua Álvaro Vindas como limite mínimo para as probabilidades de entrada em invalidez e a tabua IAPC como limite máximo para as probabilidades de morte de inválidos. A primeira foi construída em 1957 e refere-se à experiência dos segurados da "Cajá Costaricence de Seguro Social", enquanto a IAPC corresponde à experiência do extinto Instituto de Aposentadorias e Pensões dos Comerciários.

Apesar da importância dos estudos sobre invalidez, principalmente para as áreas de seguro e previdência, há carência de análises sobre este tema no Brasil e também em outros países. Merino et al. (2003) chamam atenção para a falta de estudos nesta área e para a demanda, cada vez maior, de trabalhos sobre este tema na Espanha. Além da importância para as áreas de seguro e previdência, estes autores observam que, com a crescente preocupação dos agentes sociais com a provisão social, é necessário desenvolver técnicas para avaliar os custos futuros com invalidez e incapacidade.

Segundo Benjamin e Pollard (1980), a mortalidade dos aposentados por invalidez nos primeiros anos de invalidez é superior à daqueles com mesma idade que se aposentaram por invalidez há mais tempo. Isto acontece porque os indivíduos com piores condições de saúde tendem a morrer nos primeiros anos de invalidez. Este efeito seletivo tende a desaparecer com o aumento da duração da invalidez.

As tábuas de mortalidade clássicas consideram que as probabilidades de morte para um grupo homogêneo de pessoas dependem somente da idade alcançada por elas. No caso dos aposentados por invalidez, as probabilidades de morte dependem da idade de entrada na invalidez e à duração da mesma. Na literatura atuarial, tábuas de mortalidade construídas a partir dessas probabilidades são chamadas de tábuas seletas de mortalidade (BOWERS et al., 1997).

Diante da carência e da importância dos estudos sobre invalidez, o objetivo principal deste trabalho é analisar a mortalidade dos aposentados por invalidez do Regime Geral da Previdência Social (RGPS), que rege a previdência básica, universal e compulsória, de natureza pública, dos trabalhadores do setor privado. Para tanto, foram construídas tábuas seletas de mortalidade para homens e mulheres.

$\mathrm{Na}$ elaboração das tábuas seletas de mortalidade, foram utilizados os microdados de todos os beneficiários de aposentadoria por invalidez, de clientela urbana, cujos benefícios estiveram ativos entre 01/01/1999 e 31/12/2002. Este período foi escolhido por referir-se à experiência recente dos segurados do RGPS e com objetivo de minimizar os efeitos que as mudanças nas regras de concessão de benefícios, introduzidas pela Ementa Constitucional n. 20, de 16/12/1998 (BRASIL, 1998a), possam ter causado sobre as transições dos segurados entre os estados de atividade, invalidez e morte. Os benefícios rurais não foram considerados neste estudo, devido à grande quantidade de beneficiários rurais com sexo ignorado. Até abril de 1992, esta informação não era coletada pelos postos de benefícios para os beneficiários rurais (AEPS, 2003, p. 266). 


\section{Material e métodos}

Na primeira parte desta seção, descrevem-se os dados utilizados neste estudo e suas limitações. A seguir são apresentados os métodos empregados na construção das tábuas seletas de mortalidade para os segurados do RGPS, o que inclui: definir o que são tábuas seletas de mortalidade e como construí-las; descrever como foram calculadas as taxas de mortalidade, por idade alcançada do segurado e duração da invalidez; e descrever os métodos de graduação utilizados para suavização das taxas de mortalidade.

\section{Os dados disponíveis e suas limitações}

Entre os 2.362.835 beneficiários de aposentadoria por invalidez, de clientela urbana, que estiveram ativos por algum momento no período de estudo, 8.700 $(0,37 \%)$ foram excluídos da análise porque não apresentavam informações sobre as datas de nascimento ou os dados existentes eram inconsistentes com as datas de início e/ou de cessação de benefícios. Dos 2.354.135 beneficiários restantes, 328.723 apresentavam data de cessação dos benefícios, dos quais $68,24 \%$ eram homens, $28,72 \%$ mulheres e $3,05 \%$ estavam registrados como sexo ignorado. Entretanto, o fato de um benefício apresentar data de cessação no período de estudo não é suficiente para considerá-lo cessado por óbito ou por outro motivo, podendo ter sido suspenso. A suspensão ocorre quando há suspeita de irregularidade nas condições que levaram à sua concessão e manutenção, ou quando há suspeita de morte do beneficiário. Dos benefícios com data de cessação no período de estudo, 94,09\% encontravam-se efetivamente cessados e $5,91 \%$ suspensos, sendo que, desses últimos, $94,47 \%$ foram suspensos pelo Sistema Informatizado de Controle de Óbitos (Sisobi), que capta informação dos Cartórios de Registro Civil. Esses são obrigados por lei (artigo 68 da Lei 8.212, de julho de 1991, com redação dada pela Lei 8.870, de 15 de abril de 1994), a fornecer à Previdência Social, até o dia 10 de cada mês, o registro dos óbitos ocorridos no mês anterior (BRASIL, 1998b). A Dataprev (Empresa de Processamento de Dados da Previdência Social) identifica os beneficiários mortos, a partir da comparação das informações de sua base de dados de beneficiários com aquelas enviadas pelos cartórios, referentes ao nome do falecido, nome da mãe, sexo, data e local de nascimento, etc. O benefício é considerado suspenso pelo Sisobi quando, embora haja evidências do óbito do beneficiário, essas não são suficientes para considerá-lo cessado.

Além do óbito, há outros motivos para cessação dos benefícios de aposentadoria por invalidez. $\mathrm{Na}$ base de dados disponibilizados para este trabalho, a variável motivo de cessação apresenta as seguintes categorias: óbito; recuperação da capacidade de trabalho ou volta voluntária ao trabalho; concessão de outra espécie ou transformação; e outros motivos. Na Tabela 1, são apresentados os motivos de cessação dos benefícios, no período 1999-

TABELA 1

Distribuição percentual dos benefícios de aposentadoria por invalidez do RGPS cessados, por sexo, segundo motivo de cessação

Brasil-01/01/1999 a 31/12/2002

\begin{tabular}{lcccc}
\hline \multicolumn{1}{c}{ Motivo } & \multicolumn{3}{c}{ Sexo } \\
\cline { 2 - 5 } & Masculino & Feminino & Ignorado & Total \\
\hline Óbito & 92,66 & 83,16 & 83,13 & 89,73 \\
Recuperação da capacidade laborativa e volta ao & & 0,43 & 0,04 & 0,3 \\
trabalho & 0,26 & 0,33 & 0,08 & 0,27 \\
Fraude ou erro administrativo & 0,25 & 0,15 & 0,02 & 0,17 \\
Transformação ou concessão de outro benefício & 0,18 & 15,94 & 16,73 & 9,55 \\
Outros & 6,65 & 100,00 & 100,00 & 100,00 \\
Total & 100,00 & $(85.989)$ & $(9.310)$ & $(309.243)$ \\
& $(213.944)$ & & &
\end{tabular}

Fonte: Ministério da Previdência Social. Dataprev. 
2002. De todos os benefícios cessados, 49 não apresentavam informação sobre o motivo.

Observa-se, na Tabela 1, que uma parte expressiva dos benefícios cessados, principalmente para as mulheres, foi classificada na categoria outros motivos. Uma tabulação destes benefícios, segundo os motivos de cessação que compõem esta categoria, foi solicitada ao Dataprev. Assim, verificou-se que $99,53 \%$ dos benefícios de aposentadorias por invalidez, urbanos e rurais, classificados como cessados por outros motivos, o foram por estarem suspensos há mais seis meses. Além disso, a idade dos beneficiários na data de cessação era superior a 70 anos para mais de $70 \%$ destes benefícios, indicando que foram provavelmente cessados por morte. Então, assumiu-se, no cálculo das taxas de mortalidade, que estes benefícios foram cessados por óbito.

Dos 19.341 benefícios suspensos pelo Sisobi no período de estudo, de 01/01/1999 a $31 / 12 / 2002,18.241(94,47 \%)$ continuavam nessa situação, na data da extração dos dados, em abril de 2004, portanto, há mais de um ano. Por este motivo, tais benefícios foram considerados cessados no cálculo das taxas de mortalidade dos aposentados por invalidez. Os benefícios suspensos pelo Sisobi foram considerados cessados por óbito e os demais por outros motivos. Deste modo, somando-se os benefícios cessados por óbito e por outros motivos com aqueles suspensos pelo Sisobi, verifica-se que $98,8 \%$ do total de benefícios com data de cessação entre 01/01/1999 e 31/12/2002 foram considerados cessados por morte. Para os sexos masculino e feminino, estas porcentagens correspondem a, respectivamente, $98,9 \%$ e $98,5 \%$.

$O$ fato de os benefícios suspensos pelo Sisobi e os cessados por outros motivos terem sido considerados cessados por morte pode resultar na sobre-estimação das taxas de mortalidade, principalmente para as mulheres, para as quais o motivo outros corresponde a mais do que o dobro daquele para os homens (15,72\% contra $6,52 \%)$.

Como as cessações das aposentadorias por invalidez podem ocorrer por vários motivos, o modelo adequado para descrevê-las seria o de múltiplos decrementos. Entretanto, os números de cessações atribuídas às causas diferentes do óbito são muito pequenos (2.439 para os homens e 1.435 para as mulheres), o que dificulta a estimação das taxas de cessação por estas causas, para cada idade simples e duração do benefício de aposentadoria por invalidez. Por esse motivo, apenas o decremento de morte foi considerado.

\section{Tábuas seletas e últimas de mortalidade}

A tábua de mortalidade é um instrumento que sintetiza de forma ordenada toda a informação da variável aleatória T: o tempo de vida de um indivíduo para uma população homogênea. As probabilidades ${ }_{t} q_{x}=P(T \leq x+t \mid T \geq x)$ são condicionais à sobrevivência do indivíduo à idade x. Sob o pressuposto de que a população de interesse é homogênea quanto à sua experiência de mortalidade, nenhuma variável referente à história dos sobreviventes à idade $x$ é considerada na determinação de suas probabilidades de sobrevivência e morte futuras.

Nas situações em que se tem conhecimento de que alguma característica do indivíduo à idade x possa afetar sua sobrevivência, o pressuposto acima será inadequado para a realização de afirmações probabilísticas sobre sua sobrevivência. Os modelos de tábuas seletas de mortalidade consideram a história de invalidez dos indivíduos sobreviventes à idade $\mathrm{x}$, através da idade de entrada em invalidez e da duração da invalidez, assumindo que as probabilidades de morte dependem destas duas quantidades. Enquanto no modelo clássico de tábua de mortalidade a sobrevivência dos indivíduos é considerada desde o seu nascimento, nas tábuas seletas interessa a sobrevivência a partir da invalidez. Para cada idade de entrada em invalidez, chamada na literatura atuarial de idade de seleção, uma tábua de mortalidade pode ser construída, tendo a idade de entrada em invalidez como idade inicial. Então, para uma idade fixa de entrada em invalidez, as probabilidades de morte dependem do tempo de duração da invalidez. Os dife- 
renciais de mortalidade tendem a diminuir com o aumento da duração da invalidez. O espaço de tempo no qual o efeito da duração é importante é chamado de período de seleção. Para um período de seleção de $\mathrm{D}$ anos, probabilidades de mortalidade são calculadas para categorias de duração $0, \ldots ., \mathrm{D}-1$, em cada grupo etário. As categorias de duração $0, \ldots, \mathrm{D}-1$ referem-se aos benefícios com durações, em anos completos, desde a entrada em invalidez, isto é, com durações pertencentes aos intervalos $[0,1), \ldots,[D-1, D)$. Para durações maiores ou iguais a $\mathrm{D}$, as probabilidades de mortalidade são consideradas função somente da idade alcançada pelo segurado.

Seja $[x]$ a idade de seleção, dada pela idade do segurado na data de início do benefício de aposentadoria por invalidez, que foi considerada a idade de entrada em invalidez. Seja $q_{[x]+z}$ a probabilidade de 0 indivíduo morrer entre as idades $\mathrm{x}+\mathrm{z}$ e $x+z+t$, uma vez que ele ficou inválido na idade $x$ e encontra-se nessa situação há $z$ anos. As probabilidades ${ }_{t} q_{[x]+z}$ e cada uma das funções da tábua de mortalidade dependem agora de duas variáveis: a idade de entrada em invalidez; e a duração da invalidez. Estas funções podem ser organizadas num arranjo bi-dimensional em [x] e z, chamado na literatura atuarial de tábua seleta de mortalidade.

O desenho esquemático apresentado em Bowers et al. (1997) e reproduzido na Figura 1 ajuda a entender a idéia da tábua seleta de mortalidade. Considere uma pessoa que ficou inválida aos 30 anos. A probabilidade dela morrer no primeiro ano de invalidez é ${ }_{1} q_{[30]+0}$, de morrer no segundo ano de invalidez é ${ }_{1} q_{[30]+1}$ e assim por diante. Estas probabilidades estão representadas na primeira linha da Figura 1. A

FIGURA 1

Mortalidade seleta, final e agregada para período de seleção de 15 anos

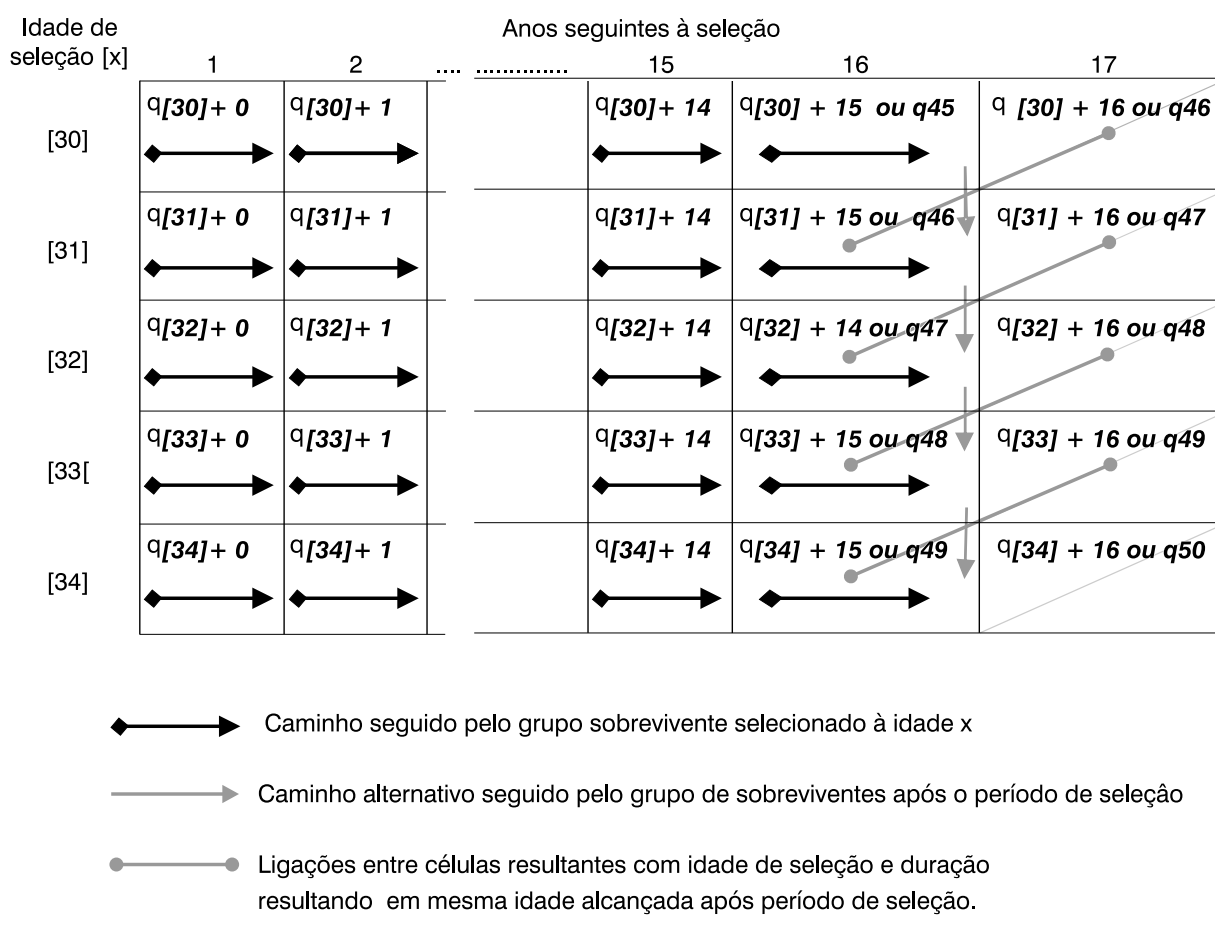

Fonte: Bowers et al. (1997). 
segunda linha contém as probabilidades de morte para uma pessoa que se tornou inválida aos 31 anos.

O impacto da duração da invalidez sobre as distribuições do tempo de sobrevivência futuro de pessoas com mesma idade deve diminuir com o aumento da duração da invalidez, de tal modo que, além do período de seleção, $\mathrm{D}$, pode-se assumir que as probabilidades de morte dependem somente da idade alcançada pelo grupo de sobreviventes, isto é:

$$
q_{[x-j]+D+j} \cong q_{[x]+D}, j>0 .
$$

No exemplo da Figura 1, no qual o período de seleção é de 15 anos, a probabilidade de uma pessoa com 45 anos de idade, que ficou inválida antes dos 30 anos, morrer no próximo ano é considerada a mesma, independente da invalidez ter acontecido aos 29 anos, aos 28 anos ou em idades ainda menores.

Considerado que o efeito da duração da invalidez não é importante após o período de seleção, o arranjo bi-dimensional descrito na Figura 1 pode ser truncado ao fim do período de seleção, resultando num conjunto de tabelas de mortalidade, chamado de tábuas seletas e última ("select and ultimate tables"). $\mathrm{O}$ arranjo resultante continua tendo um conjunto de tabelas de mortalidade, uma para cada idade de entrada em invalidez.

As probabilidades de mortes para durações além do período de seleção são expressas como função, somente, da idade do segurado. Por exemplo, para um período de seleção de 15 anos, as probabilidades de morte $q_{[30]+16}$ e $q_{[29]+17}$ são ambas expressas como $q_{46}$. A tábua de mortalidade gerada a partir das probabilidades de morte calculadas para os sobreviventes ao período de seleção é chamada de tabela última ("ultimate table"). Na Figura 1, esta tabela corresponde àquela gerada pelas probabilidades de morte $q_{45}, q_{46}, q_{47}, \ldots$, chamadas de probabilidades de morte últimas ("ultimate").

Segundo Bowers et al. (1997), as probabilidades últimas de morte, para cada idade $[x]+D$, podem ser estimadas considerando as informações sobre o número de mortes e a exposição ao risco associa- das a todas as idades de seleção menores do que $[\mathrm{x}]$ e durações maiores do que $D$, que resultem numa idade alcançada $\mathrm{x}=[\mathrm{x}]+\mathrm{D}$. Por exemplo, considerando um período de seleção de 15 anos e a idade de 20 anos como a menor idade possível para entrada em invalidez, os dados referentes às combinações de idade de seleção e duração ([20],20), ([21],19), ([22],18), ([23],17), ([24],16) e $([25], 15)$ podem ser utilizados para estimar $q_{40}$. A estimativa obtida para $q_{40}$ será uma média ponderada das estimativas de mortalidade para as diferen-tes idades de seleção.

As estimativas das probabilidades foram obtidas em função das taxas centrais de mortalidade, ${ }_{t} m_{x}$, assumindo que $\mathrm{o}$ número de sobreviventes à idade $\mathrm{x}$ varia linearmente com a idade, como ${ }_{t} q_{x}=\frac{2{ }_{t} m_{x}}{2+{ }_{t} m_{x}}$. A partir dos valores de ${ }_{t} q_{x}$, todas as outras funções da tábua de mortalidade são obtidas.

\section{Obtenção das taxas seletas e últimas de mortalidade}

Conhecidas as histórias de nascimento, invalidez e morte dos beneficiários de aposentadoria por invalidez, cujos benefícios estiveram ativos no período de estudo, estimativas das intensidades de mortalidade foram obtidas através do método da máxima verossimilhança.

Considere, inicialmente, a situação em que as intensidades de transição são funções somente da idade do beneficiário. Suponha-se que $\mathrm{M}$ mortes são observadas entre as idades $x$ e $x+1$, para um grupo de $\mathrm{N}$ beneficiários de aposentadoria por invalidez, cujos benefícios estiveram ativos durante o período de observação, que, neste estudo, vai de 01/01/1999 a 31/12/2002. Suponha-se que, no intervalo de idade $[x$, $\mathrm{x}+1$ ), o beneficiário é observado entre as idades $x+t_{i}, 0 \leq t_{i} \leq 1$, e $x+u_{i}, t_{i} \leq u_{i} \leq 1$. Sob o pressuposto de que, entre as idades $x$ e $x+1$, a taxa instantânea de mortalidade, $\mu(t)=\lim _{\Delta t \rightarrow 0} \frac{P(T \leq t+\Delta t \mid T \geq t)}{\Delta t}, t \geq 0$, é constante, o estimador de máxima verossimilhança de $\mu$ é 


$$
\widehat{\mu}=\frac{M}{\sum_{i=1}^{N}\left(u_{i}-t_{i}\right)}
$$

No numerador, tem-se o número de mortes ocorridas entre as idades $x$ e $x+1$ $e$, no denominador, a soma dos tempos de exposição ao risco para todos os beneficiários entre as idades $x$ e $x+1$. 0 estimador de máxima verossimilhança, $\bar{\mu}$, é também obtido quando a variável aleatória $\mathrm{M}$, número de transições da invalidez para morte, segue uma distribuição Poisson com intensidade de transição $\mu$ e média e variância $\lambda=\mu \sum_{i=1}^{N}\left(u_{i}-t_{i}\right)$.

Para durações de invalidez menores do que $D$, as intensidades de transição dependem da idade do beneficiário e do tempo de duração da invalidez. Neste caso, o estimador de $\mu$ é obtido assumindo que é constante na região $[x, x+1) x[z, z+1)$, onde $z$ é a duração da invalidez. O estimador resultante tem a mesma forma daquele obtido acima, com a diferença de que M é o número de mortes e $\sum_{i=1}^{N}\left(u_{i}-t_{i}\right)$ é o tempo total de exposição ao risco observados na região $[x, x+1) x[z, z+1)$.

Para estimar as taxas de mortalidade dos inválidos, por idade e duração, são necessárias as datas de nascimento, de início e de cessação de benefício. Estas datas foram disponibilizadas de forma incompleta pelo MPS/Dataprev. As de nascimentos restringiram-se ao ano e as datas de início e cessação de benefícios, aos meses e anos de ocorrência destes eventos. Para solucionar este problema, adotou-se o procedimento utilizado por Zayats (1999 e 2005), que, ao construir tábuas seletas de mortalidade para os beneficiários de seguro-incapacidade da "Social Security American" (SSA), fez os dias e meses de nascimento coincidirem com os dias e meses de início de benefício. Nos trabalhos de Zayatz, isto foi feito para facilitar o cálculo dos tempos de exposição ao risco de cessação dos benefícios dentro de cada região $[x, x+1) x[z, z+1)$, pois, desta forma, os aniversários dos benefícios e beneficiários coincidem. Dada a ausência de informação sobre os dias das ocorrências dos eventos nascimento, início e cessação de benefícios, estes eventos foram alocados ao $15^{\circ}$ dia dos respectivos meses de suas ocorrências.

Os tempos de exposição de cada beneficiário dentro de cada região $[x, x+1) x[z, z+1)$ foram obtidos como no exemplo seguinte. Considere um beneficiário que nasceu em 1950, ficou inválido em maio 1995 e teve o benefício cessado em setembro de 2002. O tempo de observação para este beneficiário, neste estudo, começa em de 01 de janeiro de 1999 e termina em 15 de setembro de 2002. Então, para este beneficiário, tem-se que:

- nascimento: 15 de maio de 1950;

- início de benefício: 15 de maio de 1995;

- idade na DIB: 45 anos;

- início do período de observação: 01 de janeiro de 1999;

- idade no início do período de observação: 48,63 anos;

- idade em anos completos no início do período de observação: 48 anos.

- duração do benefício no início da observação: 3,64 anos;

- duração em anos completos no início do período de observação: 3 anos;

- fim do período de observação: 15 de setembro de 2002;

- idade no fim do período de observação: 52,35 anos;

- idade em anos completos no fim da observação: 52 anos.

Os tempos de exposição ao risco de morte deste beneficiário, para as combinações de idades e duração observadas, entre 01/01/1999 e 31/12/2002, são apresentados na Tabela 2.

Os tempos de exposição e o número de óbitos foram calculados para cada combinação de idade simples e duração, a partir das informações de todos os beneficiários cujos benefícios estiveram ativos no período de estudo. Isto foi feito, separadamente, para cada sexo. Os tempos pessoas-ano de exposição e o número de mortes para os beneficiários com sexo 
TABELA2

Tempos de exposição ao risco de morte por duração e idade alcançada para um beneficiário hipotético com 45 anos completos na data de início de benefício (DIB)

\begin{tabular}{cccc}
\hline $\begin{array}{c}\text { Idade na DIB } \\
\text { (anos completos) }\end{array}$ & Duração & $\begin{array}{r}\text { Idade alcançada } \\
\text { (anos completos) }\end{array}$ & Exposição \\
\hline & 3 & 48 & 0,37 \\
45 & 4 & 49 & 1 \\
& 5 & 50 & 1 \\
& 7 & 51 & 1 \\
& 7 & 52 & 0,35 \\
\hline
\end{tabular}

Fonte: Elaboração própria.

ignorado foram distribuídos proporcionalmente entre os sexos masculino e feminino, a partir das distribuições destas quantidades, por idade simples e duração, observadas para cada sexo.

Obtidos os números de mortes e a soma dos tempos pessoas-ano de exposição ao risco de mortalidade, para cada combinação de idade alcançada pelo beneficiário e duração do benefício de aposentadoria por invalidez, foram calculadas estimativas das taxas de mortalidade, usando os estimadores de máxima verossimilhança.

\section{Graduação das taxas de mortalidade}

Graduação é o processo pelo qual as taxas ou probabilidades de morte, ou de outro decremento de interesse, são suavizadas. É esperado que, comparadas às taxas brutas de mortalidade, as taxas suavizadas reflitam, mais proximamente, a variação existente nas verdadeiras e desconhecidas taxas de mortalidade. A graduação assegura que o modelo de sobrevivência resultante apresente grau de suavidade, de modo que as funções calculadas a partir dele, tais como as quantidades atuariais de prêmios e reservas matemáticas, também compartilhem esta propriedade (HABERMAN e PITTACO, 2000).

Os dados usados para graduar as intensidades de morte dos aposentados por invalidez consistem num conjunto de $\mathrm{n}$ pares ordenados $\left(i_{u}, e_{u}\right)$, definidos sob um arranjo de células indexadas por $u$. As quantidades $i_{u}$ e $e_{u}$ são, respectivamente, o número de mortes e o tempo total de exposição ao risco observados para a célula u. Nos casos em que a mortalidade depende da idade alcançada pelo segurado e da duração da invalidez, cada célula u corresponde a uma região $[x, x+1) x[z, z+1)$ e $\left(i_{u}, e_{u}\right)=\left(i_{x, z}, e_{x, z}\right)$, onde $\mathrm{x}$ é a idade alcançada pelo segura do e z, a duração da invalidez. Nos casos em que a mortalidade depende somente da idade alcançada, as células $\mathrm{u}$ referemse aos intervalos etários $[x, x+1) \mathrm{e}$ $\left(i_{u}, e_{u}\right)=\left(i_{x}, e_{x}\right)$. Os valores de $\left(i_{u}, e_{u}\right)$ foram obtidos como descrito anteriormente, na seção Tábuas seletas e últimas de mortalidade.

Embora os segurados do RGPS estejam expostos ao risco de invalidez desde a sua filiação no sistema, o que pode acontecer a partir dos 15 anos, neste estudo foram considerados somente os dados obtidos para idades de entrada em invalidez entre 20 e 70 anos. Para o período de estudo, há poucos casos de invalidez antes dos 20 anos. A idéia inicial era considerar, como limites máximos para concessão de aposentadoria por invalidez, as idades mínimas exigidas para concessão de aposentadorias por idade aos trabalhadores urbanos: de 60 anos, para as mulheres; e 65 anos, para os homens. Entretanto, há um contingente expressivo de aposentadorias por invalidez concedidas após estas idades, principalmente para as mulheres. Assim, na construção das tábuas de mortalidade, 70 anos foram estabelecidos como a idade máxi- 
ma de entrada em aposentadoria por invalidez.

Para objetivos da modelagem, os dados de cada célula $\left(i_{x, z}, e_{x, z}\right)$ foram alocados aos pontos médios dos intervalos de idade alcançada $[x, x+1)$ e duração $[z, z+1)$. Por exemplo, os valores observados de $\left(i_{x, z}, e_{x, z}\right)$ para a região $[30,31) x[3,4)$ foram alocados aos pontos médios 30,5 anos e 3,5 anos. Procedimento semelhante foi adotado por Renshaw e Haberman (1995).

Para graduar as intensidades de mortalidade dos inválidos, foram utilizados modelos de Poisson. Suponha-se que as quantidades $i_{u}, \mathrm{u}=1, \ldots . \mathrm{n}$, são variáveis aleatórias independentes, com distribuição de Poisson, com média $E\left(i_{u}\right)=\lambda_{u}=e_{u} \mu_{u}$, onde $\mu_{u}$ é o tempo pessoas-ano de exposição ao risco de morte observado para a célula u e $\mu_{u}$ corresponde à intensidade de mortalidade que se deseja estimar.

O logaritmo do número esperado de mortes, $\lambda_{u}$, pode ser escrito como:

$$
\ln \left(\lambda_{u}\right)=\ln \left(e_{u} \mu_{u}\right)=\ln \left(e_{u}\right)+\ln \left(\mu_{u}\right),
$$

com $\ln \left(e_{u}\right)$ assumido conhecido e considerado termo "offset" do modelo, isto é, uma variável independente com coeficiente conhecido igual a 1. O logaritmo da intensidade de mortalidade é modelado como $\ln \left(\mu_{u}\right)=\sum_{i}^{p} h_{i}(u) \beta_{i}$. As quantidades $h_{i}(u)$ são as $\mathrm{p}$ variáveis explicativas definidas como funções $u=(x, z)$, nos modelos para as mortes ocorrendo dentro do período de seleção, e como função de $u=x$, nos modelos para o número de mortes ocorrendo além do período de seleção. No primeiro modelo, as variáveis $h_{i}(u)$ foram expressas como polinômios ortogonais (DRAPER e SMITH, 1998) para idade e o logaritmo da duração do benefício, e como termos de interação entre esses dois polinômios. A transformação logarítmica para a variável duração da invalidez mostrou-se apropriada, tendo em vista que as diferenças entre as intensidades de mortalidade tendem a diminuir com o aumento da duração. No modelo das mortes ocorrendo além do período de seleção, foi considerado um polinômio ortogonal para idade alcançada pelo segurado.
O modelo de Poisson pertence à classe dos modelos lineares generalizados, para os quais os estimadores de máxima verossimilhança dos parâmetros do modelo podem ser obtidos pelo método iterativo de mínimos quadrados ponderados. Mais detalhes podem ser obtidos em McCullagh e Nelder (1989) e Cameron e Triverdi (1998).

Os resíduos de Pearson $r_{u}=\frac{\left(i_{u}-\hat{\lambda}_{u}\right)}{\sqrt{\hat{\operatorname{Var}}\left(i_{u}\right)}}$, com $\hat{\operatorname{Var}}\left(i_{u}\right)$ uma estimativa da variância de $\mathrm{i}_{\mathrm{u}}$, foram utilizados para detectar a falta de ajuste do modelo.

Depois de ajustados os modelos para as mortes ocorrendo dentro e fora do período de seleção, estimativas das taxas de mortalidade dos aposentados por invalidez foram obtidas como $\hat{\mu}_{u}=\exp \left(\sum_{i}^{p} h_{i}(u) \hat{\beta}_{i}\right)$ A partir destas estimativas, tábuas seletas e últimas de mortalidade foram construídas para homens e mulheres.

Considerou-se como último grupo etário das tábuas de vida o intervalo 100 anos e mais. $\mathrm{O}$ número de anos vividos a partir da idade $100, \mathrm{~L}_{100+}$, foi calculado dividindo o número de sobreviventes nesta idade pela taxa de mortalidade $m_{100+}$, calculada como a média das taxas de mortalidade obtidas para as idades maiores ou igual a 100 anos, ponderadas pelo número de sobreviventes na idade $\mathrm{x}$, isto é,

$m_{100+}=\frac{\sum_{x \geq 100} m_{x} l_{x}}{\sum_{x \geq 100} l_{x}}$.

\section{Resultados}

Os tempos pessoas-ano de exposição ao risco de morte, os números de mortes observados e as taxas de mortalidade estimadas para os aposentados por invalidez do RGPS, cujos benefícios iniciaram dos 20 aos 70 anos e estiveram ativos por algum instante entre 01/01/1999 e 31/12/ 2002, foram calculados por idade de início e duração do benefício, para cada sexo. Os benefícios com durações maiores ou iguais a 25 anos foram agregados numa única 
categoria de duração. O total dos tempos pessoas-ano de exposição ao risco de morte utilizado na estimação das taxas de mortalidade dos beneficiários foi de 4.612.349,61, para homens, e 3.006.045,42, para as mulheres, e o total de mortes correspondeu, respectivamente, a 227.821 e 94.422 .

As taxas de mortalidade foram graduadas através do ajuste de modelos de Poisson. Para cada sexo, dois modelos foram ajustados. O primeiro, denominado Modelo Idade e Duração, para as mortes ocorrendo dentro do período de seleção, no qual as taxas de mortalidade dependem da idade alcançada pelo beneficiário e da duração do benefício. O segundo, chamado de Modelo Idade, para as mortes ocorrendo além do período de seleção, no qual as taxas de mortalidade dependem somente da idade alcançada pelo beneficiário. Períodos de seleção de 20 e 25 anos, respectivamente, foram considerados para homens e mulheres. Os períodos de seleção foram escolhidos de modo que a transição entre as estimativas

\section{GRÁFICO 1}

Logaritmo das taxas estimadas pelos modelos Idade e Duração e Idade, para homens, por idade alcançada pelo segurado e duração do benefício

Brasil - 01/01/1999 a 31/12/2002

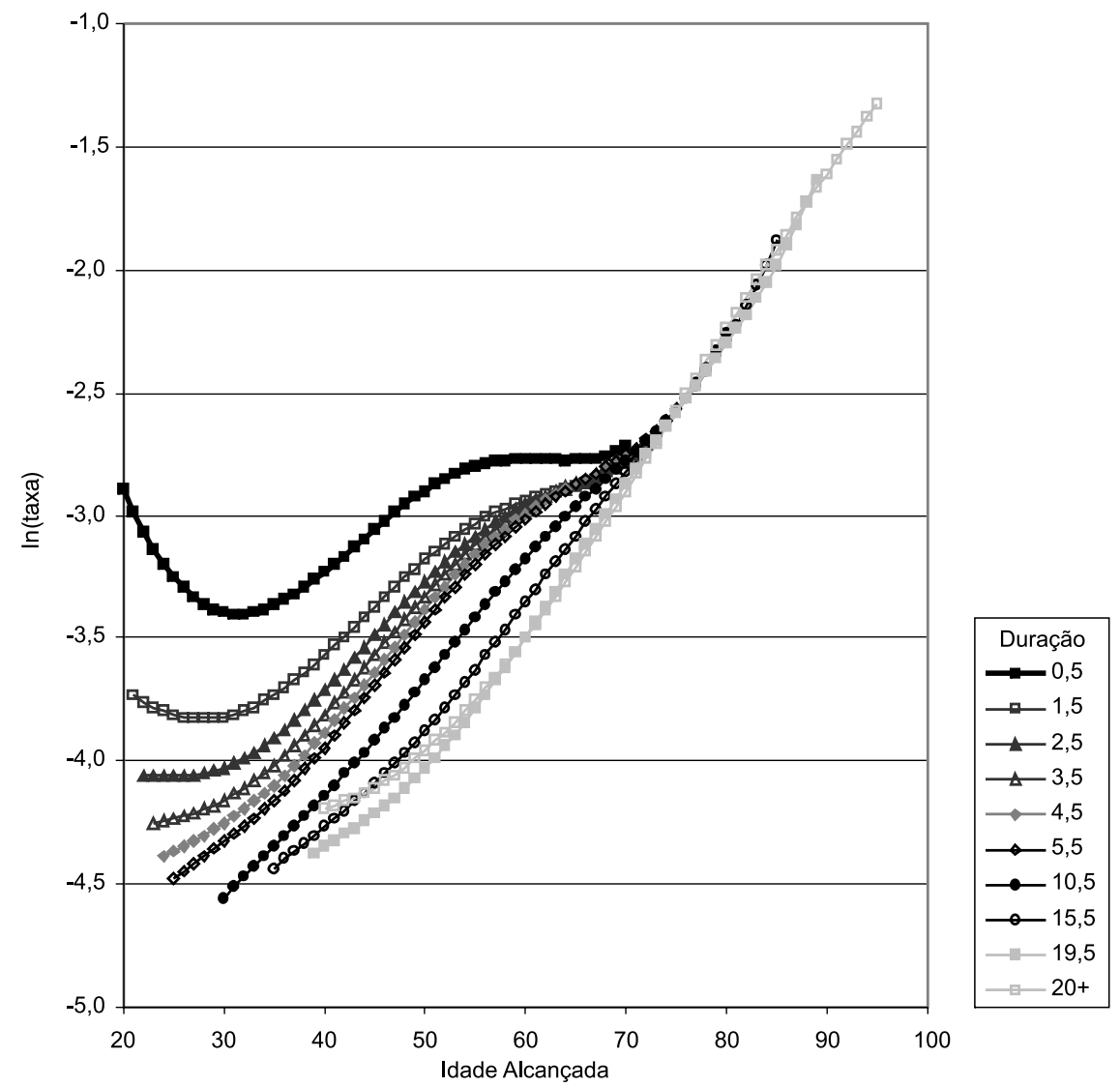

Fonte: Ministério da Previdência Social. Dataprev. 
graduadas das taxas de mortalidade referentes ao último ano do período de seleção e as estimativas das taxas últimas ocorressem de forma suave.

Para o sexo masculino, o Modelo Idade e Duração ajustado tem como preditores lineares um polinômio de quinto grau para a idade alcançada pelo segurado, um polinômio de terceiro grau para logaritmo da duração e interações entre os termos de ordem menor ou igual a quatro do primeiro polinômio com os termos do segundo polinômio. Para o sexo feminino, o modelo ajustado tem como preditores lineares um polinômio de quarto grau para idade alcançada, um polinômio de terceiro grau para o logaritmo de duração e termos de interação entre eles. Para cada sexo, o modelo idade ajustado tem como preditor linear um polinômio de terceiro grau para idade alcançada pelo beneficiário.

Nos Gráficos 1 e 2 são apresentadas as taxas de mortalidade estimadas pelo Modelo Idade e Duração e pelo Modelo Idade, segundo idade alcançada, para algumas durações, respectivamente, para homens e mulheres.

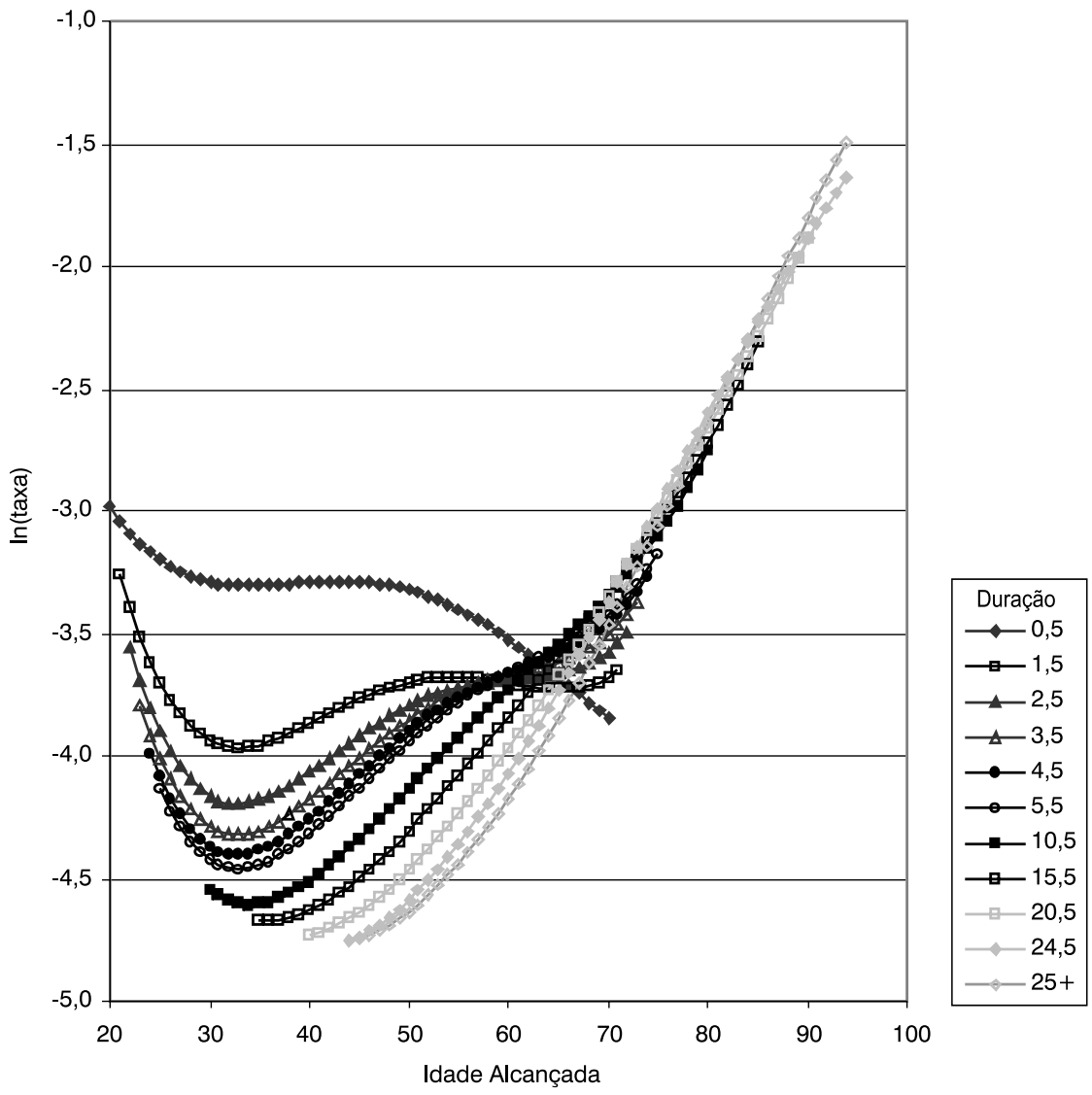


Nota-se, nos Gráficos 1 e 2, que o efeito da duração da invalidez sobre a mortalidade é maior nos primeiros anos de duração do benefício e tende a diminuir com a idade. O maior impacto é observado entre as duas primeiras durações. Para idades superiores a 70 anos, as taxas de mortalidade são muito parecidas, independentes de duração. De certa forma isto é esperado, pois, sendo a morte um evento certo, a heterogeneidade nas probabilidades de morte dos sobreviventes deve diminuir, quanto mais próxima estiver a idade máxima para a vida humana.

No Gráfico 1, observa-se que as taxas de mortalidade graduadas para durações maiores ou iguais aos 20 anos são menores do que aquelas obtidas para algumas durações menores, para idades inferiores ou igual a 60 anos. $O$ esperado seria que estas taxas fossem tão pequenas quanto aquelas calculadas para a duração igual a 19,5 anos. Uma das explicações para isso pode ser a pior qualidade das informações para os benefícios mais antigos, isto é, com maiores durações. Por esse motivo, para construção da tábua de vida para o sexo masculino, as taxas de mortalidade para estas idades e duração 20 anos e mais foram consideradas iguais àquelas obtidas para duração igual a 19,5 anos. No Gráfico 2 alguns pontos merecem destaque. Primeiro, as taxas de mortalidade das mulheres no primeiro ano de recebimento do benefício de aposentadoria por invalidez diminuem à medida que aumenta a idade alcançada, mesmo nas mais avançadas. Isto é explicado, em parte, pelo fato de que, no primeiro ano de benefício, praticamente $50 \%$ das mortes ocorrem entre os aposentados por neoplasias, que é uma importante causa de invalidez nas idades mais jovens. Segundo, para as idades acima de 60 anos (a idade mínima para concessão de aposentadoria por idade), existe um efeito seletivo da duração, ao contrário do esperado (Gráfico 2). Parcela significativa das aposentadorias por invalidez ocorre, entre as mulheres, depois dos 60 anos, quando há maior incidência de conces- são de benefícios por doenças ósseomusculares, para as quais menores taxas de mortalidade são esperadas.

A partir das taxas suavizadas, tábuas seletas e últimas de mortalidade foram construídas para cada sexo. A última idade alcançada considerada nos Modelos Idade foi 95 anos, para homens e mulheres. Taxas de mortalidade para idades além dos 95 anos dependem somente da idade alcançada pelo beneficiário. Elas foram obtidas assumindo que aos 120 anos as taxas de mortalidade de homens e mulheres são iguais a 1,e interpolando linearmente os logaritmos das taxas de mortalidade das idades 95 e 120 anos.

As probabilidades de morte $q_{[x]+z}$, para homens e mulheres, são apresentadas nas Tabelas 3 e 4 e as esperanças de vida, $e_{[x]+z}$, nas Tabelas 5 e 6 . Nestas tabelas, as diagonais em negrito correspondem a uma mesma idade alcançada e diferentes durações. Por exemplo, na Tabela 4, referente aos homens, os valores na primeira diagonal em negrito, de cima para baixo, correspondem às probabilidades de os aposentados por invalidez, que alcançaram 30 anos, morrerem no próximo ano, para diferentes durações do benefício. A probabilidade de morte, para um segurado que se aposentou aos 30 anos, é igual a 0,331, enquanto para um aposentado com 30 anos, que sobreviveu ao primeiro ano de benefício, é igual a 0,0219. Estas probabilidades continuam declinando com o aumento da duração, de tal modo que a probabilidade de um aposentado com 30 anos e duração de benefício igual a dez anos morrer no próximo ano é igual a 0,0158 .

Para os aposentados por invalidez até os 30 anos, as esperanças de vida para duração igual a 0 foram menores do que aquelas observadas para a duração igual a 1, reflexo da maior diferença observada entre as probabilidades de morte para estas duas durações nas idades mais jovens. Nota-se, também nas Tabelas 5 e 6, que o efeito da duração sobre as esperanças de vida diminui conforme aumenta a idade alcançada. 

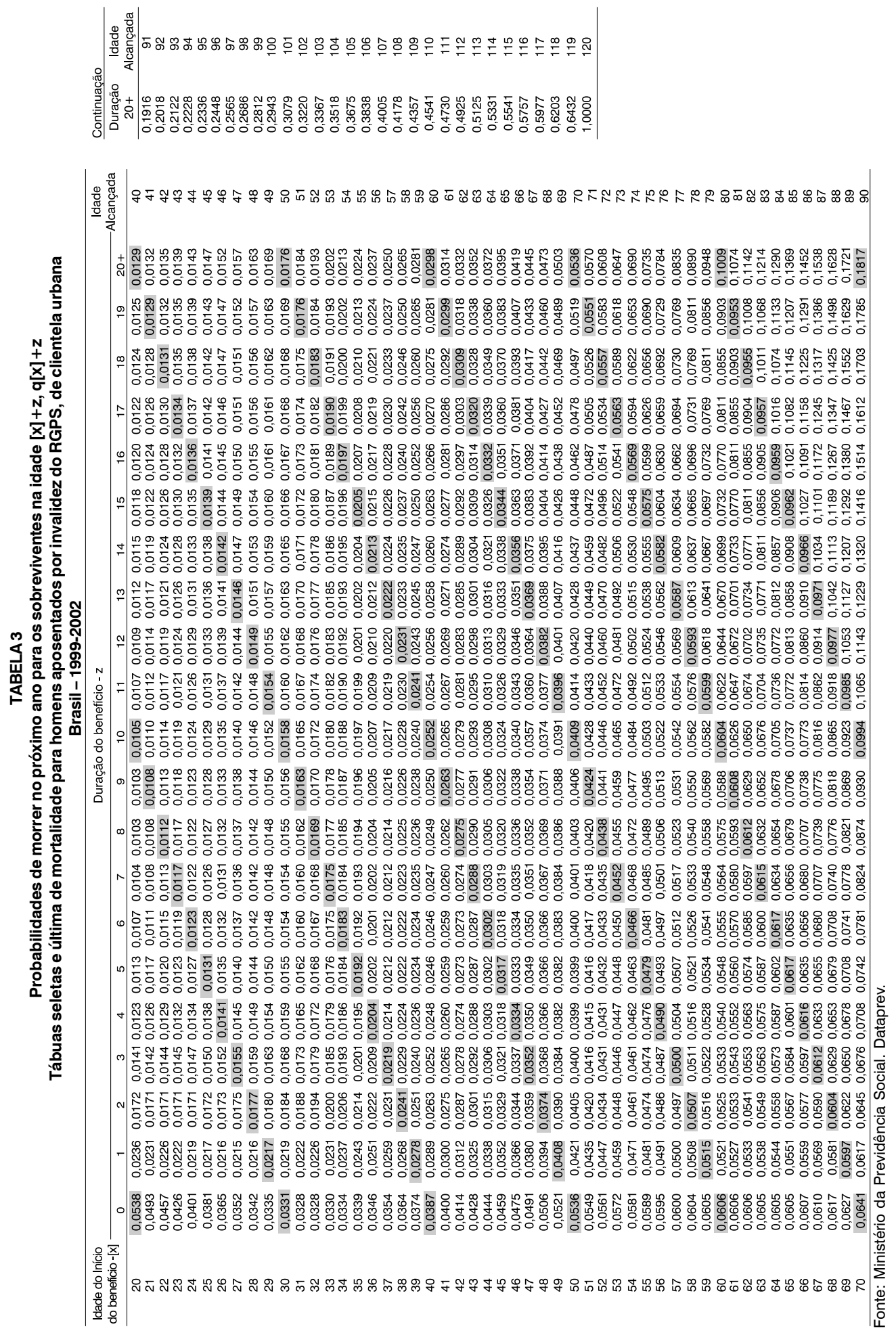


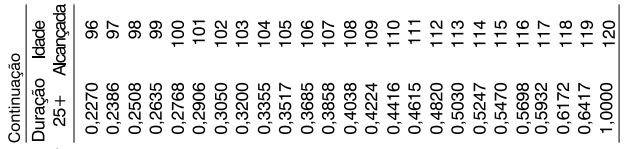

焉营

+ +

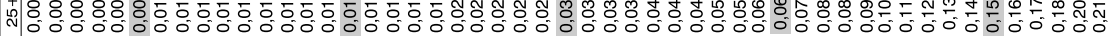

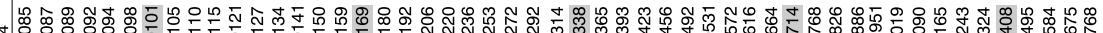
N m

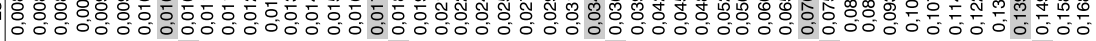

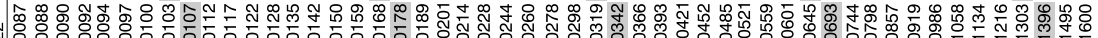

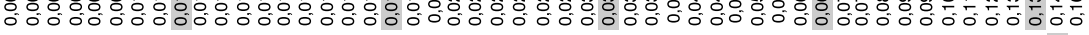

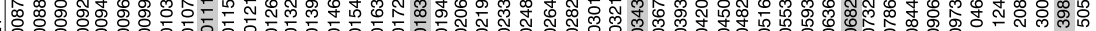

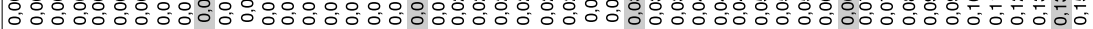

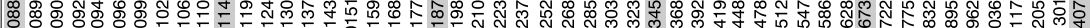

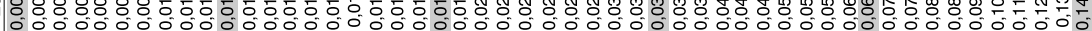

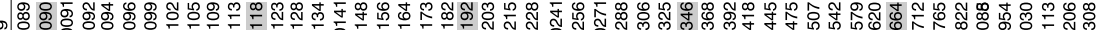
-

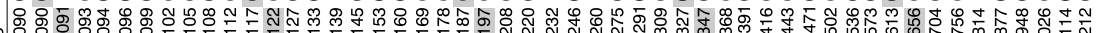

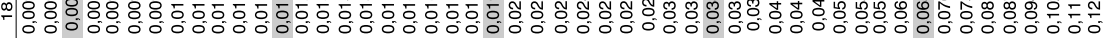

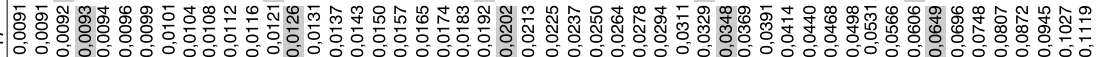
海

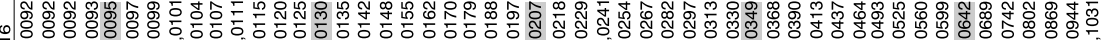

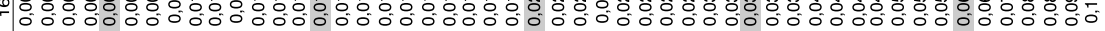

Љ \% \%

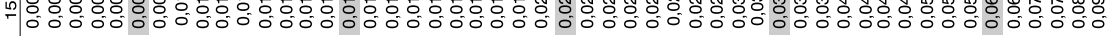
† o

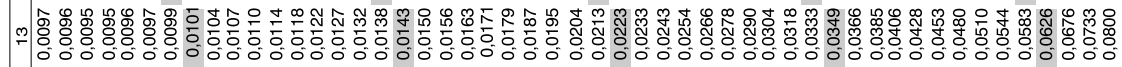

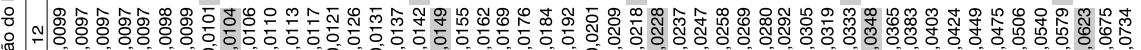
要

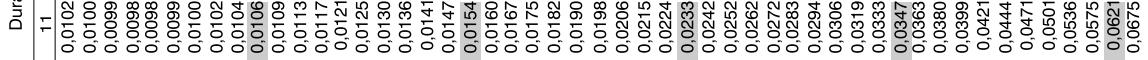

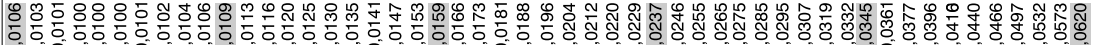

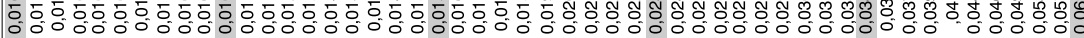

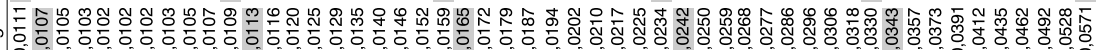

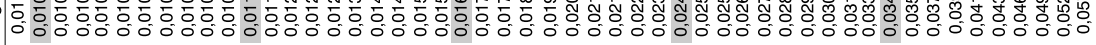

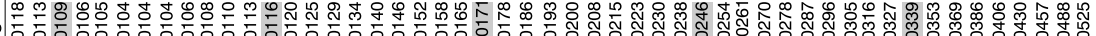

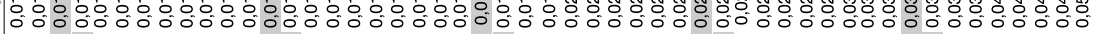

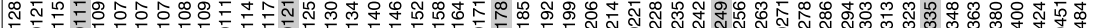

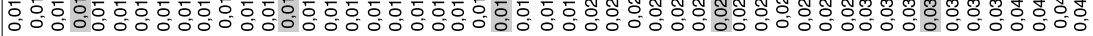

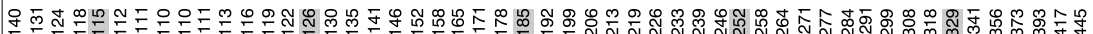

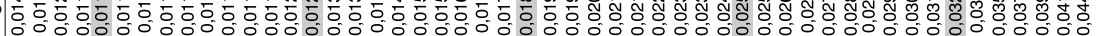
舟 ᄂ ᄂ

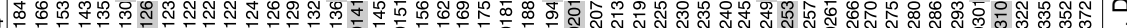

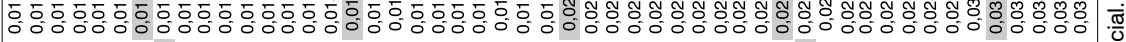
స్

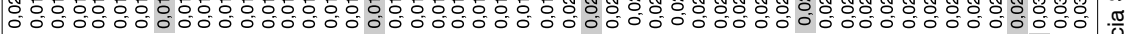

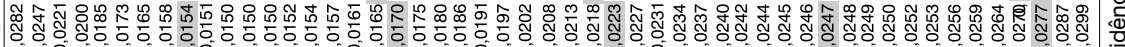

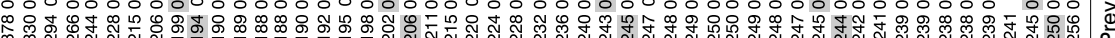

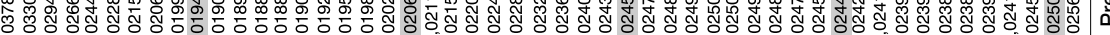

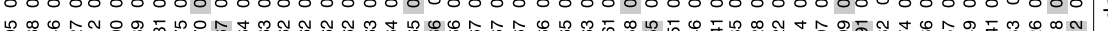

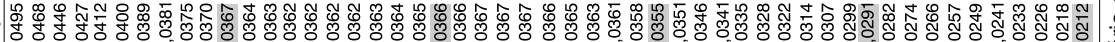
을 $\frac{\mathbb{1}}{1}$

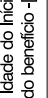

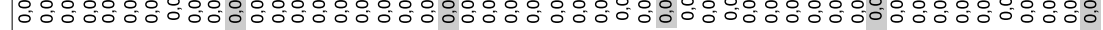

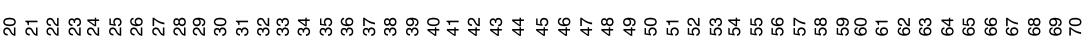



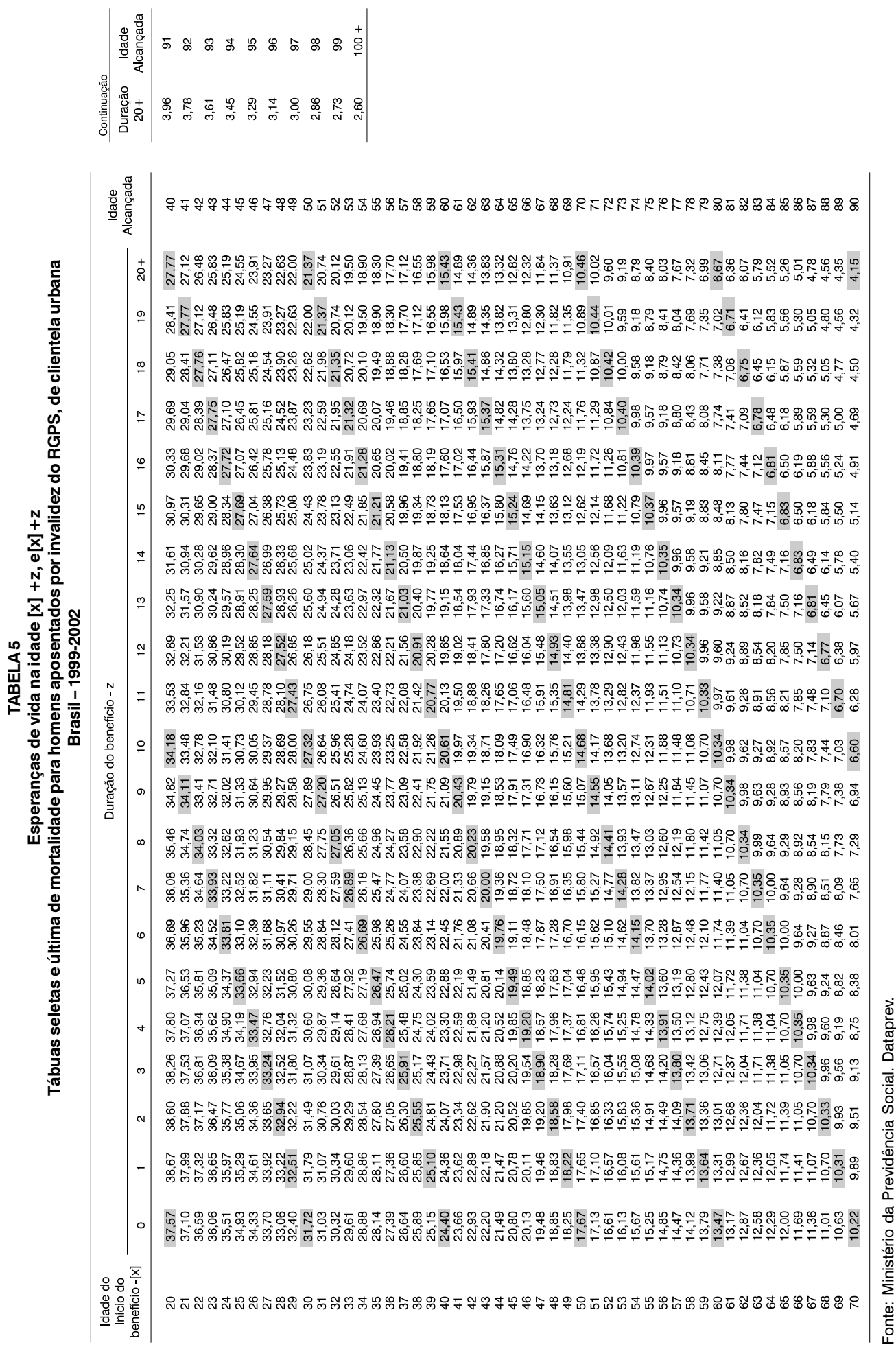


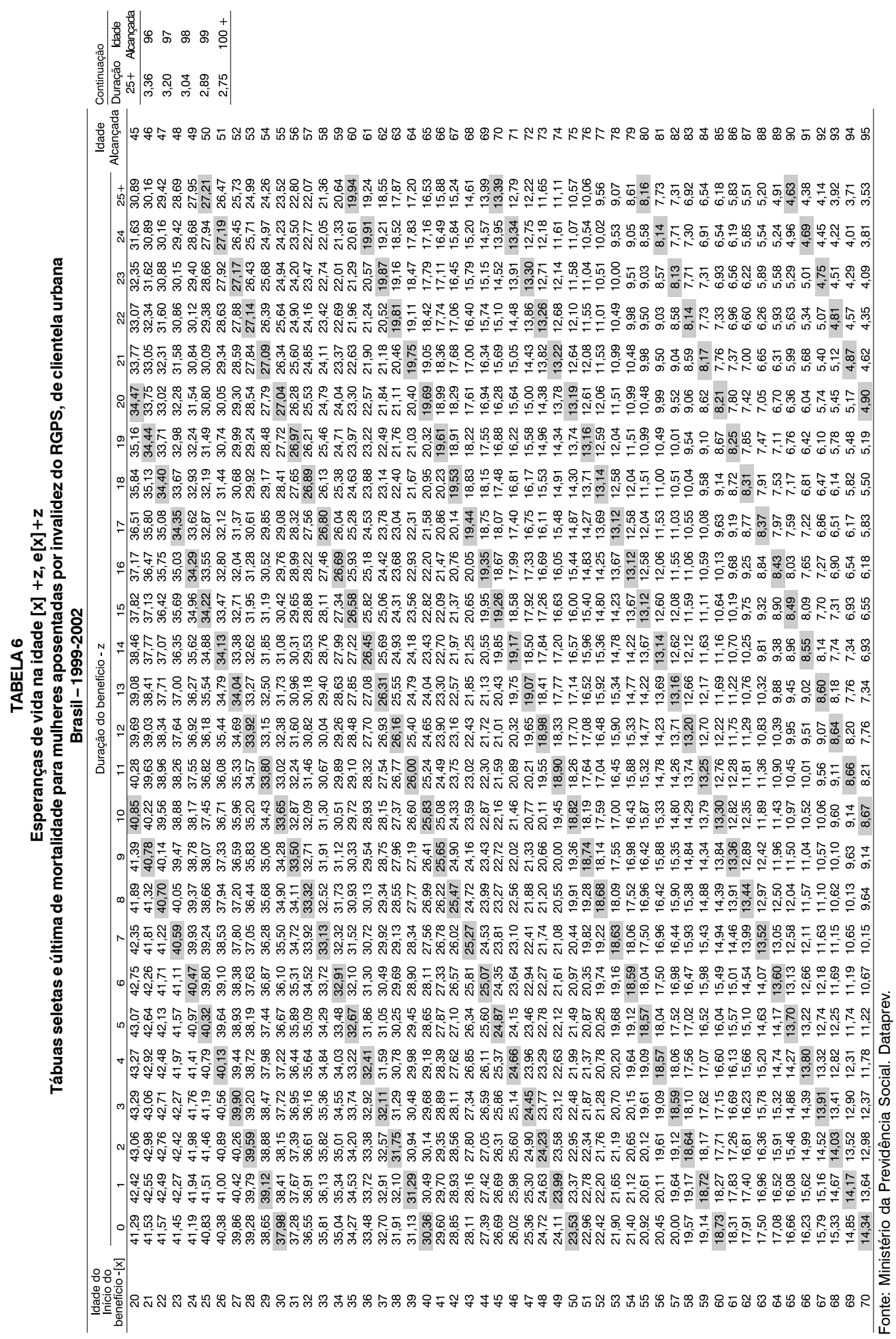




\section{Considerações finais}

Neste estudo, procurou-se retratar o processo de mortalidade dos aposentados por invalidez, de clientela urbana, do Regime Geral da Previdência Social. Com este objetivo foram construídas tábuas seletas e últimas de mortalidade para cada sexo, a partir dos registros administrativos da Dataprev, relativos a todos os beneficiários de aposentadoria por invalidez, cujos benefícios estiveram ativos entre 01/01/1999 e 31/12/2002.

Com exceção das idades muito jovens de entrada em invalidez, as mulheres apresentam, nos primeiros anos de aposentadoria, probabilidades de morte menores do que os homens, o que indica que os homens aposentam-se em condições de saúde mais precárias do que as mulheres.

Como observa Vallin (2005), "a muIher, mais propensa à moderação, exer-

\section{Referências bibliográficas}

MPS/DATAPREV/INSS. Anuário Estatístico da Previdência Social: Aeps 2002. Brasília: v.10, [2003].

BENJAMIN, B.; POLLARD, J.H. The analysis of mortality and other actuarial statistics. $2^{\text {a. }}$ ed. London: Institute of Actuaries and the Faculty of Actuaries, 1980.

BOWERS, N.J.; GERBER, H.U.; HICKMAN, J.C.; JONES, D.A.; NESBIT, C.J. Actuarial mathematics. Schaumburg, Illinois: The Society of Actuaries, 1997.

BRASIL. Decreto n. 3.048 de 6 de maio 1998. Diário Oficial da União, Brasília 07 de maio de 1999. Seção I, p. 50-108. Disponível em: <http://www81.dataprev.gov.br/sislex/ paginas/23/1999/3048.htm >. Acesso em: $11 / 06 / 2005$.

. Emenda Constitucional n. 20 de dezembro de 1998. Diário Oficial da União, Brasília, 16 de dezembro de 1998a. Disponível em: <http://www81.dataprev.gov.br/ sislex/paginas /30/1998/20.htm>. Acesso em: 11/06/2005.

. Lei n 8.213, de 24 de julho de 1991 - Lei Orgânica da Previdência Social. Diário cendo atividades menos nocivas e de maneira provavelmente mais respeitadora de sua saúde, mais inclinada a cuidar de seus corpos e preservar suas vidas, as mulheres souberam naturalmente tirar melhor proveito dos progressos médico e social". Isto, provavelmente, contribui para que elas se aposentem por invalidez em melhores condições de saúde e também para que, uma vez aposentadas por invalidez, vivam em média mais tempo do que os homens.

Muito pouco se conhece sobre a mortalidade da população brasileira e menos ainda a respeito da mortalidade dos aposentados por invalidez. Espera-se que os resultados obtidos sejam úteis para compreender estes processos e também para a Previdência Social na realização de projeções de beneficiários e de gastos futuros com aposentadorias por invalidez.

Oficial da União, Brasília, 14 de agosto de 1998b. Disponível em: <http://www81. dataprev.gov.br/ sislex/paginas/42/1991/ 8212.htm>.

CAMERON, A.C.; TRIVEDI, P.K. Regression analysis of count data. Cambridge: Cambrige University Press, 1998.

CONSELHO NACIONAL DE SEGUROS PRIVADOS (CNSP). Resolução n. 092 de 30 de setembro de 1992. Diário Oficial da União, Brasília, 10 de outubro de 2002. Disponível em: <http://w.w.w.susep.gov.br/ textos/resol092.htm>. Acesso em: 11/06/ 2005.

DRAPER, N. R.; SMITH, H. Applied regression analysis. 3. ed. NewYork: Wiley, 1998.

HABERMAN, S.; PITACCO, E. Actuarial models for disability insurance. Boca Raton: Chapman \& Hall/CRC, 2000.

McCULLAG, P.; NELDER, J.A. Generalized linear models. $2^{\text {a. }}$ ed. London: Chapman \& Hall, 1989.

MERINO, A.; GARCIA, E.P.; SOLER, J.V. Análisis dinámico de la invalidez, aplicácion 
a los seguros de riesgo. Actuários, n. 21, p. 1-31, abril/maio 2003.

MINISTÉRIO DA PREVIDÊNCIA E DA ASSISTÊNCIA SOCIAL. Portaria MPAS n. 4.992 de 05 de fevereiro de 1999. Diário Oficial da União, Brasília, 08 de fevereiro de 1999. Disponível em: <http://w.w.w81.dataprev.gov.br/ sislex/paginas/66/mpas/1999/4992.htm >. Acesso em: 11/06/2005.

RENSHAW, A.E.; HABERMAN, S. On the graduations associated with a multiple state model for permanent health insurance. Insurance: Mathematics and Economics, n. 17, p. 1-17, 1995.

RIBEIRO, A.J.F. Um estudo sobre a mortalidade dos aposentados por invalidez do Regime Geral da Previdência Social (RGPS) período 1999-2002. 174f. Tese (Doutorado em Demografia) - Centro de Desenvolvimento e Planejamento Regional, Universidade
Federal de Minas Gerais, Belo Horizonte, 2006.

VALLIN, J. Mortalidade, sexo e gênero. In: PINELLI, A. (Org.). Gênero nos estudos de população. Tradução de R. Aguiar e C. Cavalcanti. Campinas: Associação Brasileria de Estudos Populacionais, 2004.

ZAYATZ, T. Social security disability insurance program worker experience. Actuarial Study n. 118. Baltimore, junho de 2005: Social Security Administration, Office of the Chief Actuary. Disponível em: <http:/ /www.ssa.gov/OACT/NOTES /as118/ DIWorker Exper_Foreword>.

ZAYATZ, T. Social security disability insurance program worker experience. Actuarial Study n. 114. Baltimore, julho de 1999, Social Security Administration, Office of the Chief Actuary. Disponível em: <http://www.ssa.gov/ OACT/NOTES/ AS114Foreword. html>.

\section{Resumen}

Tablas de mortalidad de los pensionados por invalidez por el Régimen General de la Previsión Social, por edad de ingreso a la pensión y duración del beneficio - período 19992002

En este estudio son elaboradas tablas de mortalidad para los pensionados por invalidez del Régimen General de la Previsión Social brasileña, de clientela urbana, por sexo, utilizándose los microdatos relativos a los beneficios que estuvieron activos en algún momento del período comprendido entre 01/01/1999 y 31/12/2002.

Palabras-clave: Tablas de mortalidad. Pensionados por invalidez. Régimen General de la Previsión Social. Modelo de Poisson.

\section{Abstract}

Mortality tables of persons retired for permanent disability by the Brazilian Social Security System, per age and per beginning of retirement, between 1999 and 2002

In this study, mortality tables by sex are constructed for persons retired due to permanent disability by the Brazilian Social Security System, using data on benefits that were active at some moment during the period between January 1, 1999 and December 31, 2002.

Key Words: Mortality tables. Disability retirement. General Regime of the Brazilian Social Security System. 